\title{
The Two Phase Transitions of Hydrophobically End-Capped Poly(N-isopropylacrylamide)s in Water
}

\section{Ren, Hao}

2020-07-14

Ren , H , Qiu , X-P , Shi , Y, Yang , P \& Winnik , F M 2020 , ' The Two Phase Transitions of Hydrophobically End-Capped Poly(N-isopropylacrylamide)s in Water ' , Macromolecules , vol. 53 , no. 13 , pp. 5105-5115 . https://doi.org/10.1021/acs.macromol.0c00487

http://hdl.handle.net/10138/319659

https://doi.org/10.1021/acs.macromol.0c00487

cc_by

publishedVersion

Downloaded from Helda, University of Helsinki institutional repository.

This is an electronic reprint of the original article.

This reprint may differ from the original in pagination and typographic detail.

Please cite the original version. 


\title{
The Two Phase Transitions of Hydrophobically End-Capped Poly( $N$-isopropylacrylamide)s in Water
}

\author{
Hao Ren, Xing-Ping Qiu, Yan Shi, Peng Yang, and Françoise M. Winnik*
}

Cite This: Macromolecules 2020, 53, 5105-5115

Read Online
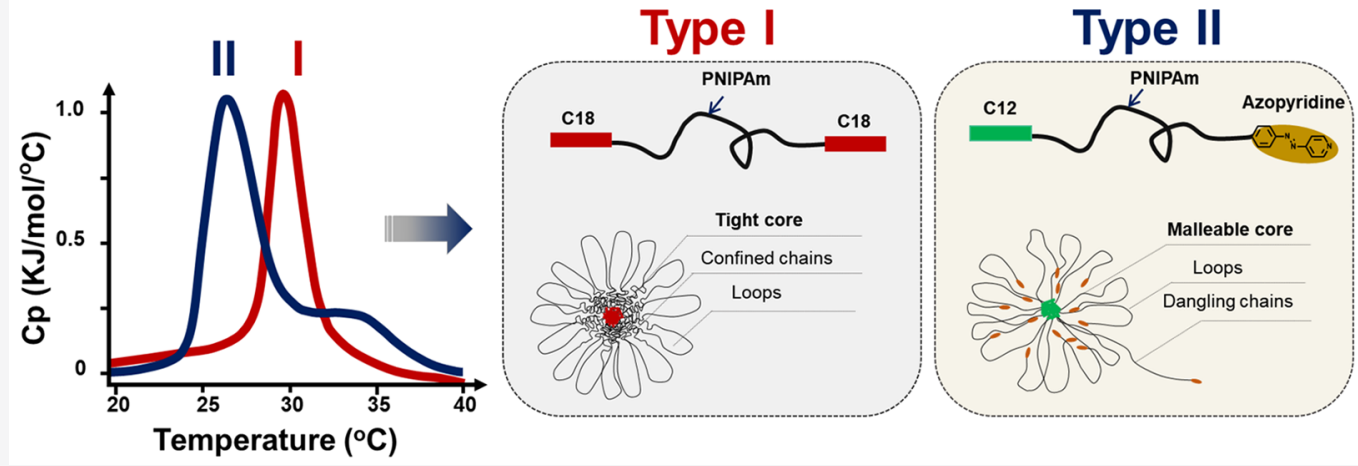

ABSTRACT: High-sensitivity differential scanning calorimetry (HS-DSC) thermograms of aqueous poly $(N$-isopropylacrylamide) (PNIPAM) solutions present a sharp unimodal endotherm that signals the heat-induced dehydration/collapse of the PNIPAM chain. Similarly, $\alpha, \omega$-di- $n$-octadecyl-PNIPAM (C18-PN-C18) aqueous solutions exhibit a unimodal endotherm. In contrast, aqueous solutions of $\alpha, \omega$-hydrophobically modified PNIPAMs with polycyclic terminal groups, such as pyrenylbutyl (Py-PN-Py), adamantylethyl (Ad-PN-Ad), and azopyridine- (C12-PN-AzPy) moieties, exhibit bimodal thermograms. The origin of the two transitions was probed using microcalorimetry measurements, turbidity tests, variable temperature ${ }^{1} \mathrm{H}$ NMR (VT-NMR) spectroscopy, and 2-dimensional NOESY experiments with solutions of polymers of molar mass $\left(M_{\mathrm{n}}\right)$ from 5 to $20 \mathrm{kDa}$ and polymer concentrations of 0.1 to $3.0 \mathrm{mg} / \mathrm{mL}$. The analysis outcome led us to conclude that the difference of the thermograms reflects the distinct self-assembly structures of the polymers. C18-PN-C18 assembles in water in the form of flower micelles held together by a core of tightly packed $n$-C18 chains. In contrast, polymers end-tagged with azopyridine, pyrenylbutyl, or adamantylethyl form a loose core that allows chain ends to escape from the micelles, to reinsert in them, or to dangle in surrounding water. The predominant low temperature $\left(T_{1}\right)$ endotherm, which is insensitive to polymer concentration, corresponds to the dehydration/collapse of PNIPAM chains within the micelles, while the higher temperature $\left(T_{2}\right)$ endotherm is attributed to the dehydration of dangling chains and intermicellar bridges. This study of the two phase transitions of telechelic PNIPAM homopolymer highlights the rich variety of morphologies attainable via responsive hydrophobically modified aqueous polymers and may open the way to a variety of practical applications.

\section{INTRODUCTION}

With the growth of nanotechnology, materials design and fabrication are converted progressively from traditional bottom-down methods, illustrated by photolithography, to bottom-up approaches based on the principles of supramolecular chemistry, which rely on the self-assembly of molecular components through weak forces. ${ }^{1,2}$ This strategy takes advantage of the faster response of supramolecular structures to external stimuli, compared to the corresponding bulk materials. ${ }^{3,4}$ The translation of supramolecular chemistry concepts into practical industrial processes has led to intense activity in the development of stimuli-responsive polymers, an important class of building blocks for the fabrication of responsive materials, particularly for medical diagnostics and therapeutics. 5,6
Poly( $N$-isopropylacrylamide) (PNIPAM), first reported in the 1950s, ${ }^{7}$ remains the thermoresponsive polymer par excellence. It dissolves readily in water at room temperature, yielding a transparent solution. A slight increase of temperature in the vicinity of $32{ }^{\circ} \mathrm{C}$ causes an abrupt and reversible change in the solution transmittance. On the molecular level, the loss of visible light transmittance corresponds to the coil-to-globule

Received: March 1, 2020

Revised: May 25, 2020

Published: June 25, 2020 


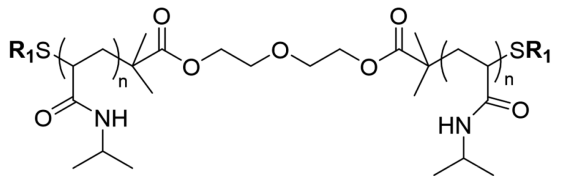

$\mathbf{R}_{1}$ :
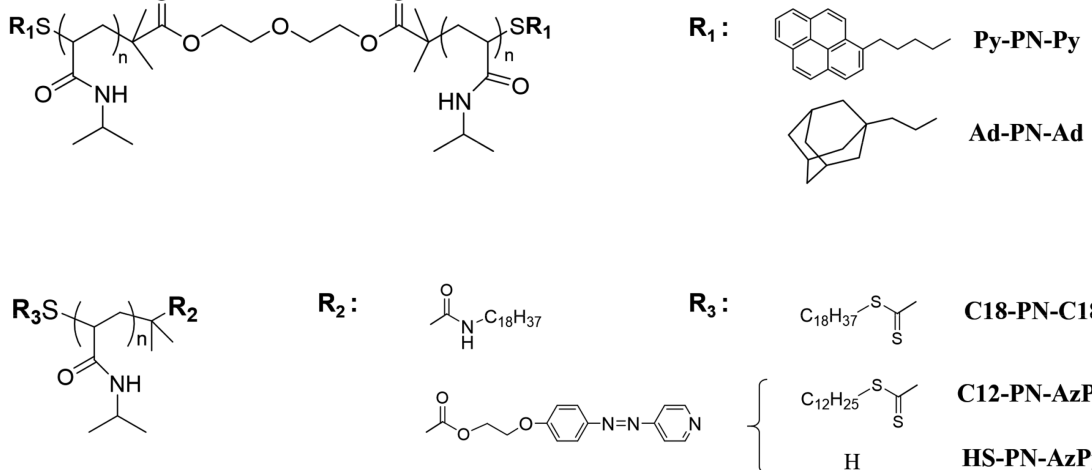

C18-PN-C18

C12-PN-AzPy

HS-PN-AzPy

Figure 1. Chemical structure of the polymers used in this study. ${ }^{32-34}$

collapse of the polymer as a consequence of the release of polymer-bound water molecules into bulk water. ${ }^{8}$ The globules aggregate into larger particles and mesoglobules that scatter light in the visible range. The polymer solution, originally clear, becomes turbid. ${ }^{9}$

Although the fraction of end-groups in a polymer chain is very small, compared to the fraction of monomer units, the termini greatly affect the conformation and association of a polymer in solution. Significant effects are observed even in the case of small end groups, such as moieties that originate from the chain transfer agents used in RAFT or ATRP polymerization. $^{10,11}$ Hydrophobically modified PNIPAMs (HMPNIPAMs) self-assemble in cold water, driven by the hydrophobic effect that promotes association of alkyl chains in water. ${ }^{12}$ When the hydrophobic groups are randomly distributed along the polymer backbone, HM-PNIPAMs form loose globular assemblies in aqueous solutions below the phase transition temperature. ${ }^{13}$ HM-PNIPAMs bearing long alkyl chains on their chain ends, $\alpha, \omega$-dialkyl-PNIPAM, form "flower micelles", ${ }^{14,15}$ where the alkyl groups assembled in the core are surrounded by hydrated PNIPAM loops, as reported earlier in the case of dialkyl-polyethylene glycols. ${ }^{16}$ Small angle neutron scattering (SANS) experiments supported by a theoretical model taking into account hydration cooperativity revealed that the PNIPAM shell of $\alpha, \omega$-di- $n$-octadecyl-PNIPAM (C18PN-C18) ${ }^{17}$ micelles contains two distinct layers: a "middle layer" formed by the part of the PNIPAM chains in close proximity to the core and an "outer (distal) layer" exposed to bulk water. Chains in the middle layer are spatially confined, whereas the PNIPAM chains in the outer layer of the shell are mobile and well hydrated. ${ }^{17}$

The incorporation of hydrophobic groups along the PNIPAM backbone or on the polymer chain ends also decreases the phase separation temperature of PNIPAM in water. This effect arises from the strong polymer/polymer interactions that result from the increased polymer density close to the core of micelles, in agreement with de Gennes' nclustering theory. ${ }^{18,19}$ The nature of the PNIPAM end group gives rise to distinct thermoresponsive properties in the case of PNIPAM terminated with small functional groups, ${ }^{10,11}$ and also in the case of linear alkyl chains, as discussed by Lang et al. in a comparative study of the ethyl- and $n$-dodecyl- groups. ${ }^{20}$

A two-layered array of PNIPAM chains similar to that of C18-PN-C18 was reported also in analyses of PNIPAM brushes grafted on nanoparticles, such as 1 or $5 \mathrm{~nm}$ gold nanoparticles (AuNPs). ${ }^{21}$ In this case, the two zones of different chain density undergo distinct phase transitions upon heating the suspension of AuNP in water. The two transitions are readily detected by high sensitivity differential HS-DSC. The lower temperature endotherm is attributed to the transition of the denser, inner part of the brush and the higher temperature transition to the less constrained outer part of the brush. ${ }^{22}$ Two phase transitions were observed earlier by Zhu and Napper upon heating aqueous dispersions of polystyrene particles tightly grafted with short PNIPAM chains, which are heated through the PNIPAM coil-to-globule temperature. $^{23}$ They attributed the lower temperature transition to attractive particle/particle interactions and the higher temperature transition to repulsive interactions among particles. PNIPAM chains of star-like topology also undergo a two-step dehydration when the branch density around the star core is high, and/or when the molar mass of the arms exceeds a threshold value. ${ }^{24,25}$ Bimodal thermograms were also reported in studies of PNIPAM-grafted nanoparticles, such as hyperbranched polyester (Boltorn H40), ${ }^{25-27}$ silica nanoparticles, ${ }^{28}$ star-like hydrophobic cores, ${ }^{24,29}$ and hydrophilic poly[oligo(ethylene glycol) methacrylate $]$ core, ${ }^{30}$ as well as A-B-A PNIPAM triblock copolymers, where A and B are polymer segments of different tacticity. ${ }^{31}$

In all the cases listed above, the bimodal thermograms were attributed to the existence of a two-layered PNIPAM shell. The inner zone formed by sterically confined PNIPAM segments undergoes a phase transition at low temperature. The mobile PNIPAM chains in the outer zone dehydrate and collapse at higher temperature. Since C18-PN-C18 flower micelles possess a two-layered shell, one would expect that the thermograms of their aqueous dispersions present two endotherms. We recorded by HS-DSC the thermogram of aqueous C18-PNC18 solutions under a variety of experimental parameters, such as solution concentration and heating rate, for polymers of molar mass from 12 to $49 \mathrm{kDa}$. In all cases, the endotherm was unimodal. ${ }^{14,32}$

We prepared recently several $\alpha, \omega$-disubstituted-PNIPAMs bearing polycyclic moieties presented in Figure 1. Two samples have identical hydrophobes at each chain end, either pyrenylbutyl (Py-PN-Py) or adamantyl-ethyl (Ad-PN-Ad). The third sample bears an $n$-dodecyl group on one end and an azopyridine group on the other end (C12-PN-AzP). The corresponding semi-telechelic AzPy-PNIPAM-SH was studied as well for comparison. We evaluated the effects of molar mass and concentration on the solutions phase transitions using turbidity experiments, HS-DSC scans, temperature-dependent ${ }^{1} \mathrm{H}$ NMR measurements, and NOESY experiments. The study leads us to emit the hypothesis that the phase transition 
properties of aqueous telechelic end modified-PNIPAM solutions is affected significantly by the morphology of the polymer micelle cores. We propose a model to account for this observation.

\section{EXPERIMENTAL SECTION}

2.1. Materials. All chemicals were obtained from Sigma-Aldrich and were used as received. Water was deionized using a Millipore Milli-Q system. The polymers employed are listed in Table 1 together

Table 1. Physical Properties of the Polymers Used in This Study

\begin{tabular}{lcrcl}
\multicolumn{1}{c}{ sample name } & $M_{\mathrm{n}}(\mathrm{g} / \mathrm{mol})$ & $\mathrm{DP}^{a}$ & $M_{\mathrm{w}} / M_{\mathrm{n}}{ }^{b}$ & \multicolumn{1}{c}{ ref } \\
Py-PN-Py 26K & 25400 & 220 & 1.07 & Fowler et al. $^{33}$ \\
Ad-PN-Ad 12K & 12000 & 103 & - & ${\text { Bennevault et } \text { al. }^{34}}_{\text {C12-PN-AzPy 5K }}$ \\
C12-PN-AzPy 7K & 7800 & 32 & 1.25 & Ren et al. ${ }^{35}$ \\
C12-PN-AzPy 12K & 12900 & 110 & 1.09 & Ren et al. $^{35}$ \\
C12-PN-AzPy 20K & 19700 & 162 & 1.02 & Ren et al. ${ }^{35}$ \\
HS-PN-AzPy 12K & 13100 & 104 & 1.14 & - \\
PNIPAM 10K & 10400 & 90 & 1.04 & Kujawa et al. ${ }^{14}$
\end{tabular}

${ }^{a} \mathrm{DP}$ from the NMR spectra of polymer solutions in $\mathrm{CDCl}_{3}$. ${ }^{b}$ Determined by GPC.

with their molecular characteristics and a link to the references that describe their preparation by reversible addition-fragmentation transfer (RAFT) radical polymerization of $\mathrm{N}$-isopropylacrylamide (NIPAM). ${ }^{33,35,36}$ Their structures are presented in Figure 1.

Preparation of $\alpha$-Azopyridine- $\omega$-thiol-poly( $N$-isopropylacrylamide) (HS-PN-AzPy). The synthesis reported previously was modified as follows: ${ }^{14,36}$ C12-PN-AzPy $12 \mathrm{~K}(0.4 \mathrm{~g}, 0.03 \mathrm{mmol})$ and the reducing agent triphenyl phosphine (TPP, $0.02 \mathrm{mg}$ ) were dissolved in THF $\left(5 \mathrm{~mL}\right.$ ). The solution was degassed with $\mathrm{N}_{2}$ for $10 \mathrm{~min}$, and subsequently, $n$-butylamine $(0.07 \mathrm{~mL}, 0.6 \mathrm{mmol})$ was added to the solution. The mixture was stirred at room temperature until disappearance of the absorption band centered at $310 \mathrm{~nm}$ attributed to the trithiocarbonate function $(\sim 1 \mathrm{~h})$. The resulting polymer (HS$\mathrm{PN}-\mathrm{AzPy} 12 \mathrm{~K}$ ) was isolated by precipitation in hexane and purified by two successive reprecipitations from THF into hexane. The structure of the product was confirmed by ${ }^{1} \mathrm{H}$ NMR spectroscopy (Figure S1).

Preparation of Polymer Solutions for Turbidity and Microcalorimetry Analysis. Polymer solutions were prepared at room temperature by dissolution in water of the desired amount of weighed freeze-dried polymer. They were kept at $5{ }^{\circ} \mathrm{C}$ in a refrigerator for $24 \mathrm{~h}$ before measurement. For $\mathrm{pH}$-dependent analyses, the solution $\mathrm{pH}$ was adjusted to the desired value by dropwise addition of $0.1 \mathrm{M}$ $\mathrm{NaOH}$ or $0.1 \mathrm{M} \mathrm{HCl}$ aqueous solutions. Turbidity and HS-DSC measurements were carried out with C12-PN-AzPy $12 \mathrm{~K}$ solutions of various concentrations between 0.1 and $3.0 \mathrm{mg} / \mathrm{mL}$, inclusively. For C12-PN-AzPy 5K and C12-PN-AzPy 7K, the measurements were performed with solutions of concentration $0.5 \mathrm{mg} / \mathrm{mL}$, due to the limited solubility of the polymers in cold water. The difference in solution concentration may affect the validity of comparative studies. $^{36}$

2.2. Characterization. Instrumentation. Routine ${ }^{1} \mathrm{H}$ NMR spectra were recorded on a Bruker $400 \mathrm{MHz}$ NMR spectrometer. The molecular weight and polydispersity of the polymers were determined with a GPC system equipped with a multi-angle laser light scattering (MALLS) detector. ${ }^{14}$ DMF containing $0.4 \% \mathrm{LiBr}$ was used as eluent, and the flow rate was set at $0.3 \mathrm{~mL} / \mathrm{min}$. UV/vis absorbance spectra were recorded on an Agilent 8483 spectrometer equipped with a Hewlett-Packard 89090 A temperature-controlled cell that was used also for turbidity measurements.

High-Sensitivity Differential Scanning Calorimetry (HS-DSC). The thermal properties of PNIPAM aqueous solutions were measured with a high-sensitivity differential scanning calorimeter (HS-DSC) from MicroCal Inc. The cell volume was $0.520 \mathrm{~mL}$. In the case of C12-PN-AzPy $12 \mathrm{~K}$, the polymer concentration ranged from 0.1 to 3.0 $\mathrm{mg} / \mathrm{mL}$. For the other polymers, the concentration was set at $1.0 \mathrm{mg} /$ $\mathrm{mL}$. The heating rate was $1.0^{\circ} \mathrm{C} / \mathrm{min}$. Each sample was subjected to three consecutive heating and cooling cycles from 10 to $70{ }^{\circ} \mathrm{C}$ to ensure repeatability. The data were analyzed with an Origin based software to subtract water as reference, and the baseline was corrected with a cubic function. The bimodal DSC traces were fitted with an asymmetric double sigmoidal Asym2Sig function using the Origin software. The fitted values of $T_{1}$ and $T_{2}$ are in good agreement with the temperatures of the minima of the endotherm derivatives ${ }^{37}$ (see Figure $2 \mathrm{~b}$ ). The low temperature endotherm (1) was defined by its maximum $T_{1}$ and its enthalpy $\Delta H_{1}$, while the broader endotherm at higher temperature was defined by its maximum $T_{2}$ and its enthalpy $\Delta H_{2}$. The enthalpies were determined from the area of the corresponding endotherm. The enthalpy of the entire signal measured experimentally was related to $\Delta H_{1}$ and $\Delta H_{2}$ by $\Delta H=\Delta H_{1}+\Delta H_{2}$. The fraction of the second peak contribution to the total enthalpy was defined as $f_{T 2}=\Delta H_{2} /\left(\Delta H_{1}+\Delta H_{2}\right)$.

Cloud Point Measurements. Samples were placed in the thermostated sample holder of the UV/vis spectrometer kept at 15 ${ }^{\circ} \mathrm{C}$ for 15 min prior to measurement. The solution transmittance at $550 \mathrm{~nm}$ was measured as a function of temperature from 15 to $60{ }^{\circ} \mathrm{C}$ at a constant heating rate of $0.5{ }^{\circ} \mathrm{C} \mathrm{min}{ }^{-1}$. The cloud point was taken (a)

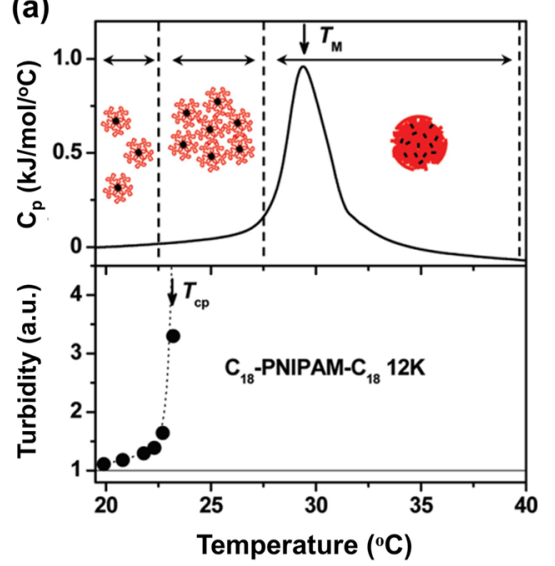

(b)

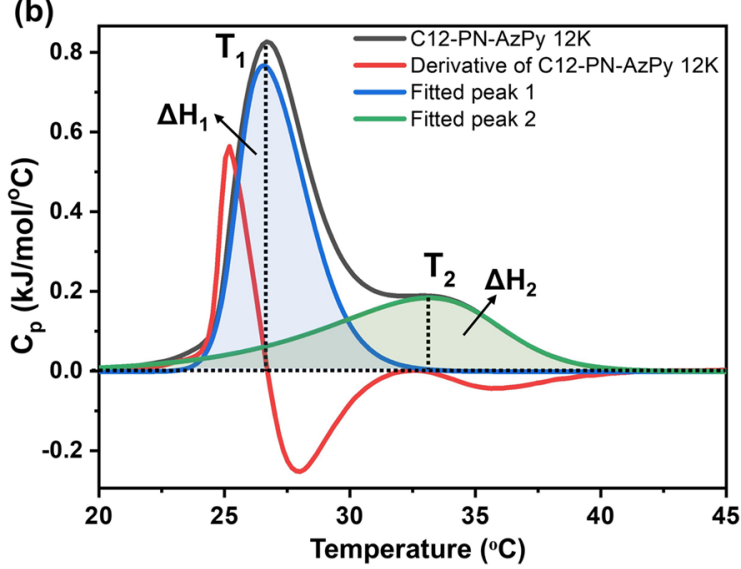

Figure 2. (a, top) HS-DSC scan and (a, bottom) turbidity curve of an aqueous solution of $\mathrm{C}_{18} \mathrm{PNC}_{18} 12 \mathrm{~K}$ (5.0 mg/mL). Reprinted with permission from ref 38. Copyright (2009) American Chemical Society. (b) HS-DSC scan of an aqueous solution of C12-PN-AzPy 12K 1.0 mg/mL, black curve) and determination of $T_{1}, T_{2}$ by peak fitting and first derivative of the HS-DSC scan. 
(a)

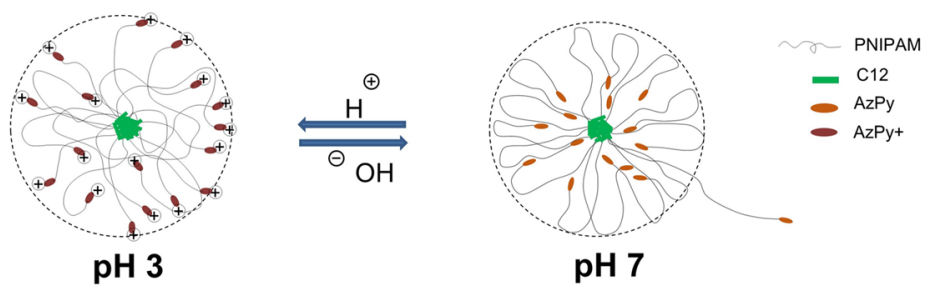

(b)

(c)
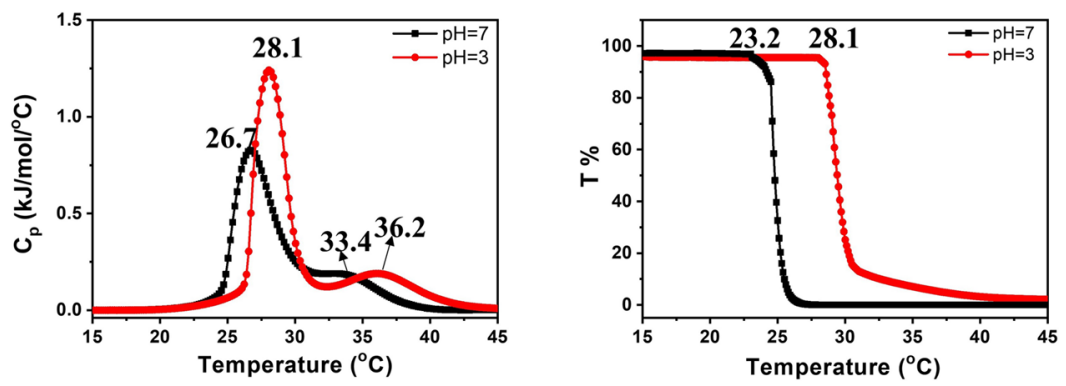

Figure 3. (a) Schematic representation of the morphology of C12-PN-AzPy micelles in water of $\mathrm{pH} 3$ and $\mathrm{pH}$ 7. (b) HS-DSC thermograms of C12-PN-AzPy $12 \mathrm{~K}$ in water $(1.0 \mathrm{mg} / \mathrm{mL}$ ) of $\mathrm{pH} 7$ (black) and $\mathrm{pH} 3$ (red). (c) Turbidity plots of solutions of C12-PN-AzPy $12 \mathrm{~K}$ in water (1.0 mg/ $\mathrm{mL})$ of $\mathrm{pH} 7$ and $\mathrm{pH} 3$.
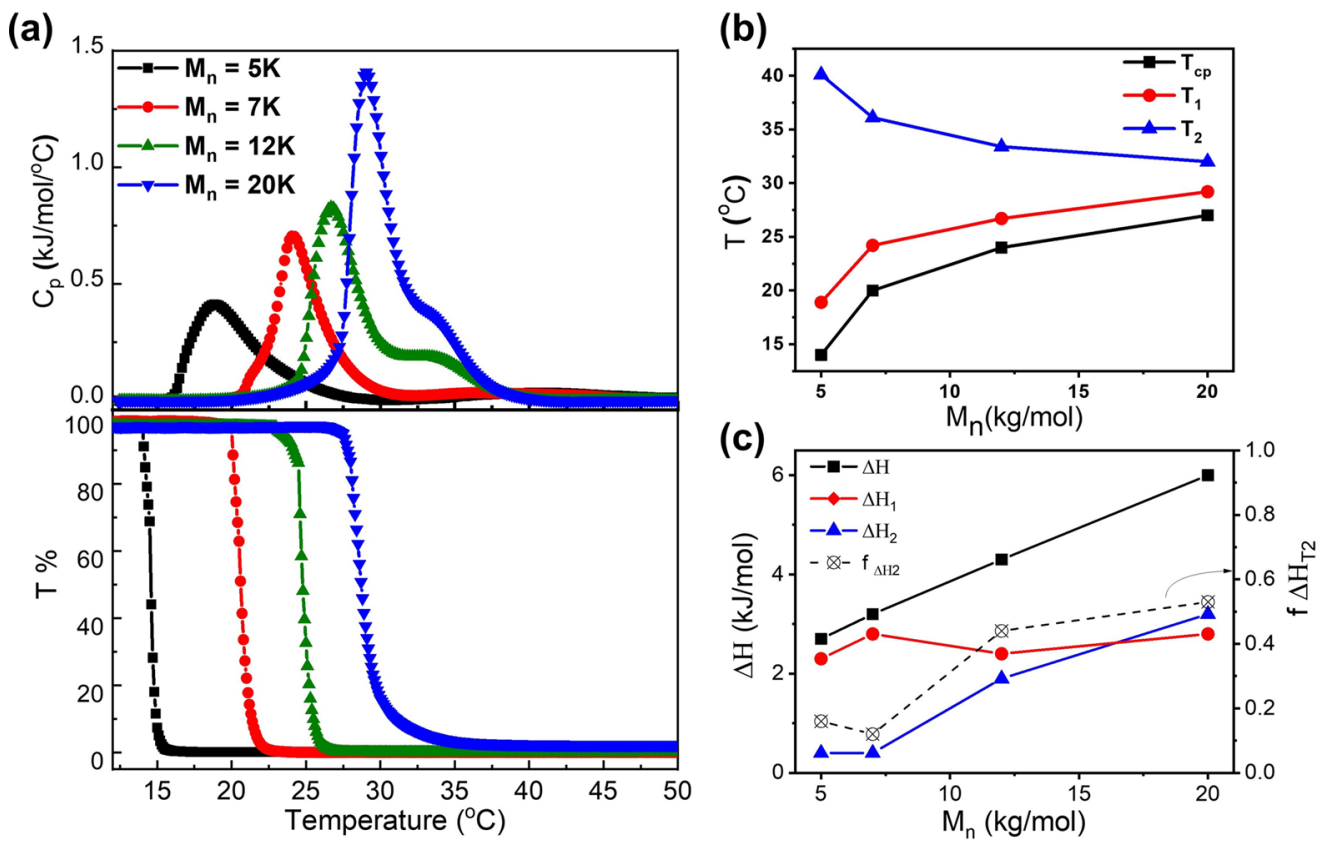

Figure 4. (a) Thermograms (top) and turbidity curves (bottom) of aqueous solution of C12-PN-AzPy of varying molar mass (concentration: 0.5 $\mathrm{mg} / \mathrm{mL}$ for polymers of molar masses $5 \mathrm{~K}$ and $7 \mathrm{~K} ; 1.0 \mathrm{mg} / \mathrm{mL}$ for polymers of molar mass $12 \mathrm{~K}$ and $20 \mathrm{~K}$ ). (b) Changes of $T_{1}, T_{2}$, and $T_{\mathrm{cp}}$ as a function of the molar mass of C12-PN-AzPy in water. (c) Changes of $\Delta H, \Delta H_{1}, \Delta H_{2}$, and $f_{T 2}$ as a function of the molar mass of C12-PN-AzPy in water.

as the temperature of the onset of the decrease in transmittance determined graphically as shown in Figure S2.

${ }^{1} \mathrm{H}$ NMR Spectroscopy Measurements. Variable temperature (VTNMR) and two-dimensional NOESY experiments were carried out on a Bruker $500 \mathrm{MHz}$ NMR spectrometer. The measurements were carried out at a polymer concentration of $3.0 \mathrm{mg} / \mathrm{mL}$ using $\mathrm{D}_{2} \mathrm{O}$ as solvent and $0.01 \mathrm{wt} \%$ of 3-(trimethylsilyl) propionic-2,2,3,3- $d_{4}$ acid sodium salt as reference. $2 \mathrm{D}$-NOESY measurements were carried out with samples kept at $15{ }^{\circ} \mathrm{C}$. For VT-NMR experiments, spectra were recorded from 15 to $45{ }^{\circ} \mathrm{C}$ with increments of $2{ }^{\circ} \mathrm{C}$. Samples were kept for $5 \mathrm{~min}$ at each temperature prior to measurement $\left({ }^{1} \mathrm{H}\right.$ NMR scan number: 128). Spectra were normalized to the integrated area of the HDO signal. The fraction $p$ of phase separated units, introduced by Speváček, ${ }^{39}$ was determined using the equation

$$
p=1-\left(I / I_{0}\right)
$$

where $I$ is the integrated intensity a given normalized signal of the polymer ${ }^{1} \mathrm{H}$ NMR spectrum in a partly phase separated system and $I_{0}$ is the integrated intensity of this signal when no phase separation occurs $\left(15^{\circ} \mathrm{C}\right)$.

Transmission Electron Microscopy (TEM). The morphology of polymeric aggregates formed in heated aqueous solutions was determined with a Tecnai T12 transmission electron microscope (TEM) at $200 \mathrm{kV}$, equipped with a $4 \mathrm{k}$ CCD camera (FEI, USA). Samples for imaging were prepared in the following procedure. One 
(a)

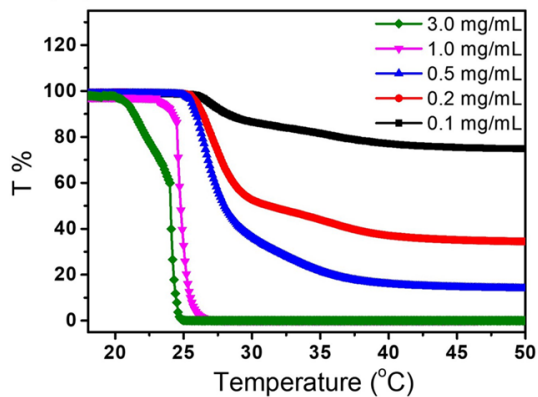

(d)

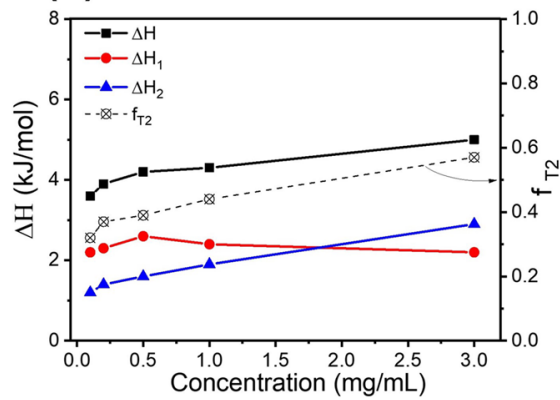

(b)

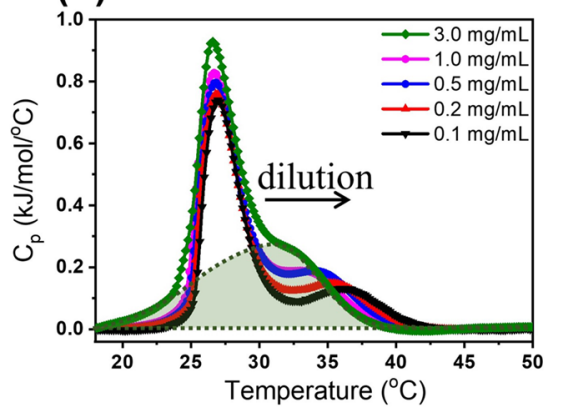

(e)

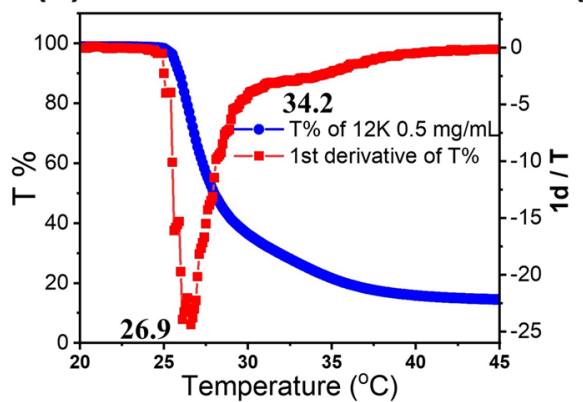

(c)

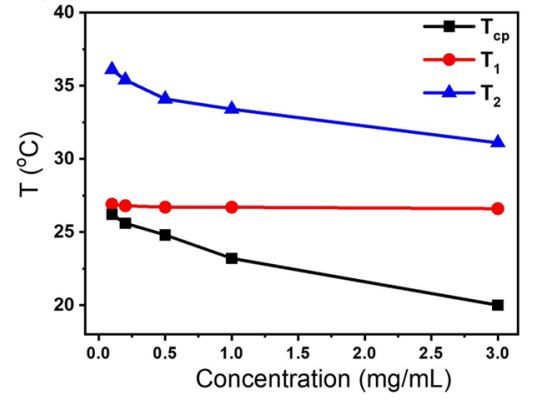

(f)

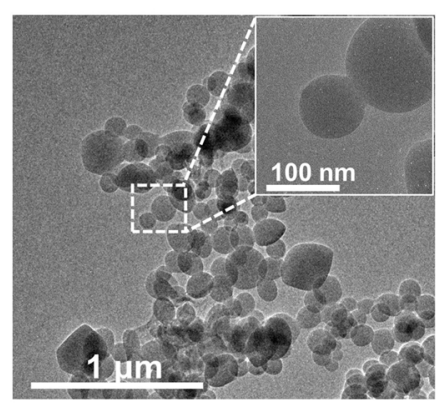

Figure 5. (a) Turbidity curves of aqueous C12-PN-AzPy $12 \mathrm{~K}$ solutions of different concentrations. (b) Normalized thermograms of aqueous C12PN-AzPy 12K solutions of different concentrations. The green hatched area is a fit to the high temperature endotherm for the $3.0 \mathrm{mg} / \mathrm{mL}$ solution (green curve, see text). (c) Changes of $T_{1}, T_{2}$, and $T_{\mathrm{cp}}$ as a function of the concentration of C12-PN-AzPy $12 \mathrm{~K}$ in water. (d) Changes of $\Delta H, \Delta H_{1}$, $\Delta \mathrm{H}_{2}$, and $f_{T 2}$ of aqueous C12-PN-AzPy $12 \mathrm{~K}$ solutions as a function of polymer concentration. (e) Turbidity curve of C12-PN-AzPy $12 \mathrm{~K}$ (0.5 mg/ $\mathrm{mL})$ and its first derivative. (f) TEM image of C12-PN-AzPy $12 \mathrm{~K}(0.5 \mathrm{mg} / \mathrm{mL})$ flash-frozen at $35{ }^{\circ} \mathrm{C}$ and freeze-dried.

drop of the polymer solution at a certain temperature was deposited on a carbon-coated copper grid placed on a filter paper. The coated grid was then placed in liquid nitrogen and subjected to freeze-drying overnight prior to TEM imaging.

\section{RESULTS AND DISCUSSION}

3.1. Solution Properties of C12-PN-AzPy in Cold Water: Brief Overview. The azopyridine derivatives investigated consist of a PNIPAM chain linked to an $n$ dodecyl group on one chain end and an azopyridine group on the other. Their structures are presented in Figure 1 and their molecular characteristics are listed in Table 1 , together with those of Py-PN-Py, Ad-PN-Ad, and other polymers used in this study. In neutral solutions, C12-PN-AzPy samples selfassemble in the form of pseudoflower micelles of $R_{\mathrm{h}} \sim 10.5$ $\mathrm{nm}$ for the sample of $M_{\mathrm{n}}=12.9 \mathrm{kDa}$. The micelles consist of an $n$-dodecyl core surrounded by a PNIPAM shell. ${ }^{35}$ The azopyridine end-groups reside within the PNIPAM shell. Their nitrogen forms an $\mathrm{H}$-bond with an amide hydrogen of a surrounding NIPAM unit (see Figure 3a). In acidic solution, the protonated azopyridinium moieties are located on the micelle periphery, forming cationic core-shell micelles. Upon heating past $\sim 25{ }^{\circ} \mathrm{C}$, aqueous suspensions of neutral or acidic C12-PN-AzPy micelles undergo a phase transition characterized by the bimodal thermograms and turbidity plots shown in Figure $3 b$ and $c{ }^{35,40}$ The transition temperature is much lower than that of a PNIPAM sample of similar molar mass devoid of hydrophobic end groups, PNIPAM-10K, prepared earlier. ${ }^{14}$ The properties of this polymer are listed in Table 1. In the following sections we describe the approach taken to explore the origin of each of the two transitions.

3.2. Temperature Dependence of the Properties of C12-PN-AzPy in Water. Polymer Molar Mass Dependence.
The thermograms and turbidity plots of aqueous solutions of four C12-PN-AzPy samples ranging in molar mass from 5 to $20 \mathrm{kDa}$ are presented in Figure $4 \mathrm{a}$, top and bottom sections, respectively. The thermograms of the four polymers display two endotherms that vary in temperature, shape, and enthalpy depending on the molar mass of the polymer. The bimodal endotherms were fitted to an asymmetric double sigmoidal (Asym2sig) function (see Experimental section and Figure 2). The fit yielded the maximum temperature and the enthalpy of each transition, $T_{1}, T_{2}$, and $\Delta H_{1}, \Delta H_{2}$, respectively, as well as the fraction of the total enthalpy attributed to the high temperature transition (transition 2). In Figure 2b, we plot the first derivative of the thermogram. The two methods yield the same $T_{1}$ and $T_{2}$ values $\left( \pm 0.5{ }^{\circ} \mathrm{C}\right)$. With increasing polymer molar mass, the maximum temperature of the second endotherm, $T_{2}$, decreases by $\sim 10{ }^{\circ} \mathrm{C}$ and the enthalpy, $\Delta H_{2}$, increases slightly, two trends commonly observed for dilute solutions of linear PNIPAM in this size range. In contrast, $T_{1}$, the maximum of the first endotherm, increases by $\sim 10{ }^{\circ} \mathrm{C}$ and the enthalpy, $\Delta H_{1}$, increases slightly with polymer mass (Figure $4 \mathrm{~b}$ and $\mathrm{c}$ ). The cloud point $\left(T_{\mathrm{c}}\right)$ of the C12-PN-AzPy solutions also increases with increasing molar mass, reaching a value of $26{ }^{\circ} \mathrm{C}$ (molar mass $20 \mathrm{kDa}$ ) (Figure 4b, black square).

Polymer Concentration Dependence. The concentration study was carried out with solutions of C12-PN-AzPy $12 \mathrm{~K}$ over a concentration range readily amenable to turbidimetry and microcalorimetry measurements $(0.1$ to $3.0 \mathrm{mg} / \mathrm{mL})$. The transmittance of the C12-PN-AzPy $12 \mathrm{~K}$ aqueous solutions of relatively low concentration (such as $0.5 \mathrm{mg} / \mathrm{mL}$, for instance, blue curve, Figure 5a) decreases sharply from 25.1 to $28.4{ }^{\circ} \mathrm{C}$. This regime is followed by a gentle drop in transmittance for $T$ $>28.4{ }^{\circ} \mathrm{C}$. The first derivative of the turbidity curve of the 

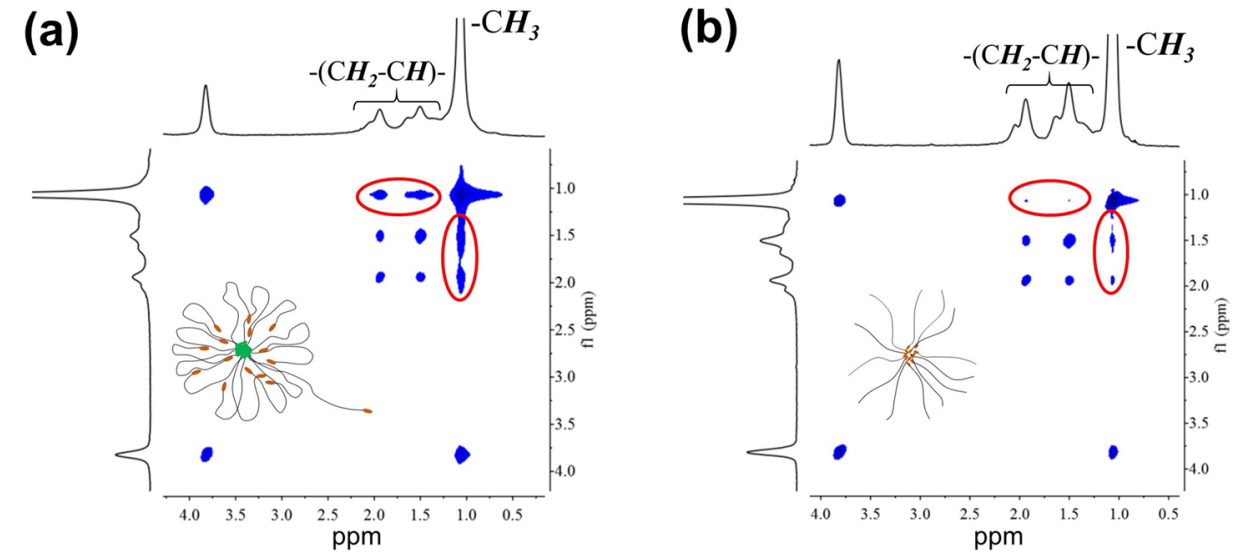

(c)
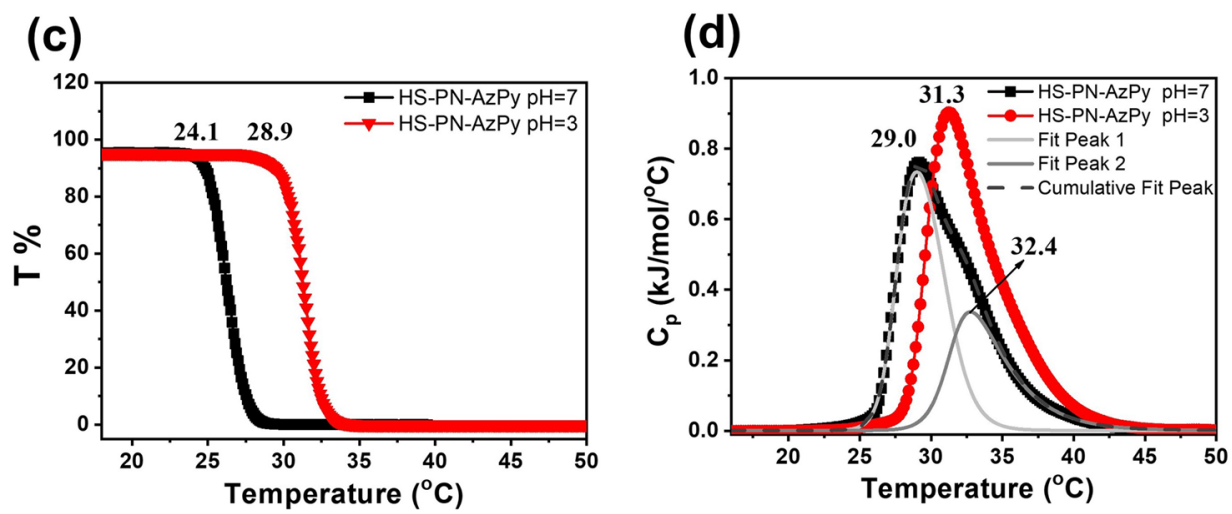

Figure 6. 2D-NOESY spectra of (a) C12-PN-AzPy 12K; (b) HS-PN-AzPy $12 \mathrm{~K}\left(3.0 \mathrm{mg} / \mathrm{mL}, 15{ }^{\circ} \mathrm{C}\right.$, in $\mathrm{D}_{2} \mathrm{O}$ ). (c) Turbidity curves and (d) thermograms of HS-PN-AzPy $12 \mathrm{~K}$ at $\mathrm{pH} 3$ and $\mathrm{pH} 7$ (in $\mathrm{H}_{2} \mathrm{O}$, concentration: $1.0 \mathrm{mg} / \mathrm{mL}$ ).

Table 2. Thermodynamic Characteristics of the Phase Transition of Aqueous Solutions of C12-PN-AzPy 12K and HS-PNAzPy 12K

$\begin{array}{llcccccc} & & \Delta H / \mathrm{kJ} \cdot \mathrm{mol}^{-1} & \Delta H_{1} / \mathrm{kJ}^{-} \cdot \mathrm{mol}^{-1} & \Delta H_{2} / \mathrm{kJ} \cdot \mathrm{mol}^{-1} & f_{T 2} & T_{1} /{ }^{\circ} \mathrm{C} & T_{2} /{ }^{\circ} \mathrm{C} \\ \text { C12-PN-AzPy } & 12 \mathrm{~K} \mathrm{pH}=7 & 4.3 & 2.4 & 1.9 & 0.44 & 26.7 \\ \text { C12-PN-AzPy } & 12 \mathrm{~K} \mathrm{pH}=3 & 4.9 & 3.1 & 2.0 & 0.41 & 28.1 \\ \text { HS-PN-AzPy } & 12 \mathrm{~K} \mathrm{pH}=7 & 5.0 & 2.9 & 2.1 & 0.45 & 29.0 \\ \text { HS-PN-AzPy } & 12 \mathrm{~K} \mathrm{pH}=3 & 5.4 & - & - & - & 31.3 & 32.4 \\ \end{array}$

C12-PN-AzPy $0.5 \mathrm{mg} / \mathrm{mL}$ solution is drawn in Figure 5e. It presents two minima at $T_{1}{ }^{\prime}=26.9{ }^{\circ} \mathrm{C}$ and $T_{2}{ }^{\prime}=34.2^{\circ} \mathrm{C}$ that correspond well with the maxima of the HS-DSC scan of the same solution presented in Figure $5 \mathrm{~b}$. Solutions of C12-PNAzPy $12 \mathrm{~K}$ of lower concentration $(0.1$ and $0.2 \mathrm{mg} / \mathrm{mL})$ exhibit the same properties (Figure S3). A transmission electron micrograph (TEM) (Figure 5f) of a C12-PN-AzPy solution flash-frozen from $35{ }^{\circ} \mathrm{C}$ to the temperature of liquid nitrogen $\left(-195{ }^{\circ} \mathrm{C}\right)$ presents aggregated particles $100-200 \mathrm{~nm}$ in diameter. The high-resolution micrograph shown in the inset of Figure $5 \mathrm{f}$ presents the encounter of two mesoglobules via a common interface, which may lead to their fusion to a larger mesoglobule.

As seen in Figure 5b, the thermograms are bimodal over the entire concentration range probed here. The maximum temperature of the first endotherm, $T_{1}\left(\sim 26.7{ }^{\circ} \mathrm{C}\right)$, does not change with polymer concentration, but both $T_{2}$ and $T_{\mathrm{cp}}$ decrease with increasing concentration (Figure 5c), a characteristic feature of the phase diagram of low molar mass linear PNIPAM chains dissolved in water as unimers. ${ }^{41}$ The enthalpy $\Delta H_{2}$ increases from $1.2 \mathrm{~kJ} / \mathrm{mol}(0.1 \mathrm{mg} / \mathrm{mL})$ to 2.9 $\mathrm{kJ} / \mathrm{mol}(3.0 \mathrm{mg} / \mathrm{mL})$, and its contribution to the total enthalpy, $f_{T 2}$, passes from 0.32 at $0.1 \mathrm{mg} / \mathrm{mL}$ to 0.57 at 3.0 $\mathrm{mg} / \mathrm{mL}$ (Figure $5 \mathrm{~d}$ ). The onset of the second endotherm of the solution of highest concentration (hatched green area of Figure $5 \mathrm{~b}$ ) ranges from 20.1 to $23.9^{\circ} \mathrm{C}$.

3.3. Solution Properties of HS-PN-AzPy 12K in Water: A Comparison of the Properties in Water of Mono- and Disubstituted-PN-AzPy of Identical Molar Mass and Concentration. The 2D-NOESY spectrum of C12-PN-AzPy $12 \mathrm{~K}$ (Figure 6a) presents strong correlation peaks at $(\delta 1.1$ ppm, $\delta 1.5 \mathrm{ppm})$ and $(\delta 1.1 \mathrm{ppm}, \delta 1.9 \mathrm{ppm})$ due to throughspace interactions between the methyl protons of the PNIPAM side chain $(\delta 1.1 \mathrm{ppm})$ and the methylene and methine main chain protons. Since through-space protons coupling only occurs between protons within a distance of $\sim 4 \AA$ or less, ${ }^{42}$ and knowing that the shortest intrachain distance between the PNIPAM methyl protons and main chain protons is $5.1 \AA$ (see calculations and Figure S4 in Supporting Information), we conclude that the correlation peaks observed in Figure 6a,b are due solely to interchain coupling. The sterically constrained environment in the PNIPAM shell of flower micelles promotes such close interchain interactions, i.e., strong correlation peaks. The correlation signals are much weaker in the 2D-NOSEY spectrum of the HS-PN-AzPy 12K solution (Figure 6b). Since the arms of star micelles are expected to be less constrained 

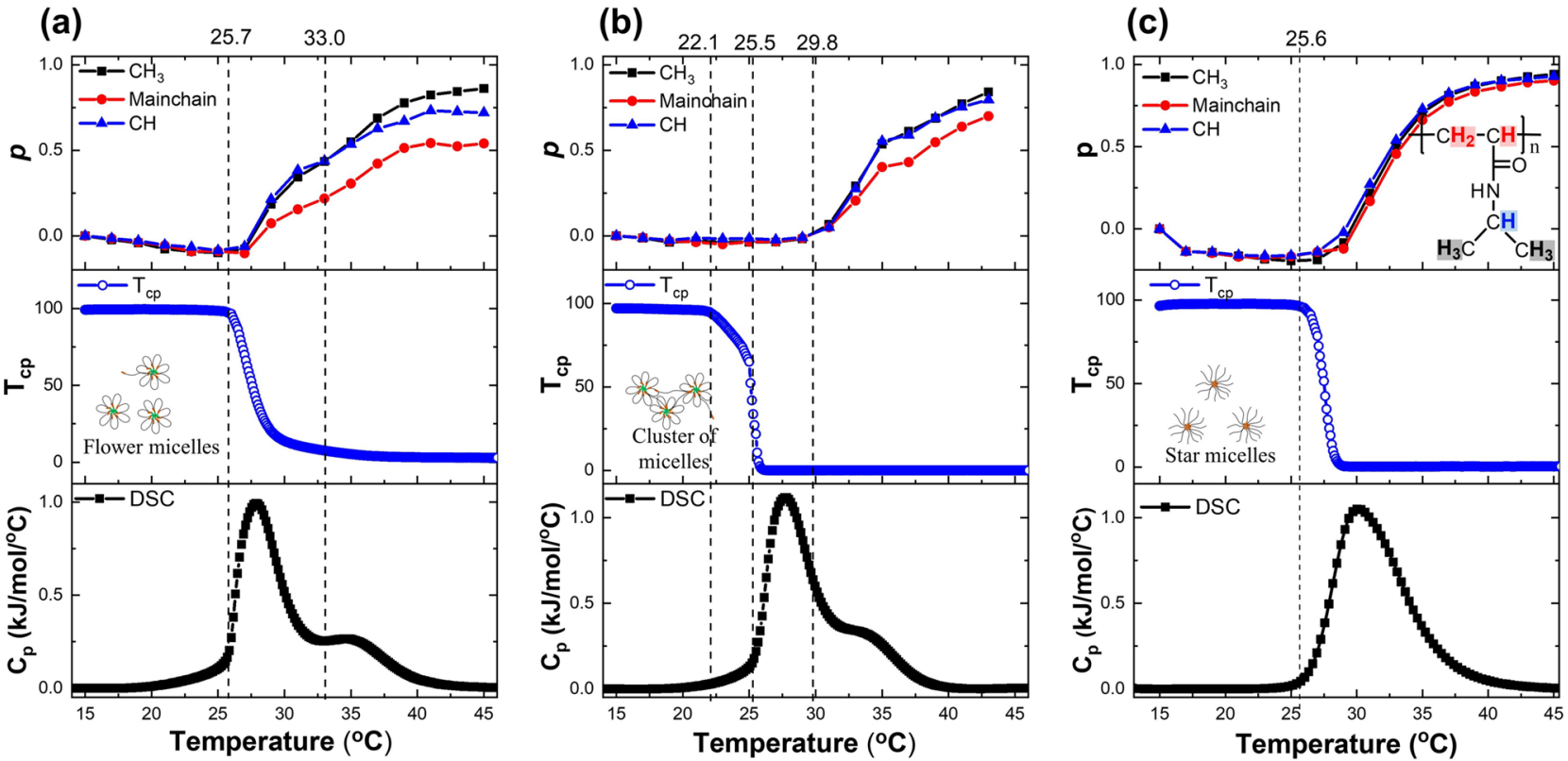

Figure 7. Temperature dependence of (top panels) the immobilized fraction $p$ of side group $\mathrm{CH}_{3}$ protons (black line), main chain protons (red line), and side group $\mathrm{CH}$ protons (blue line); (middle panel) turbidity curves; (bottom panel) HS-DSC thermograms of (a) C12-PN-AzPy 12K 0.5 $\mathrm{mg} / \mathrm{mL}$, (b) C12-PN-AzPy $12 \mathrm{~K} 3.0 \mathrm{mg} / \mathrm{mL}$, and (c) HS-PN-AzPy $12 \mathrm{~K} 3.0 \mathrm{mg} / \mathrm{mL}$ solutions in $\mathrm{D}_{2} \mathrm{O}$.

and more hydrated than the loops of flower micelles, the difference of the NOESY spectra in Figure $6 a, b$ is an indication that the HS-PN-AzPy $12 \mathrm{~K}$ chains self-assemble in water in the form of star micelles with an AzPy core and a PNIPAM shell formed by HS-terminated PNIPAM arms.

The cloud point of HS-PN-AzPy $12 \mathrm{~K}$ in water is slightly higher than that of C12-PN-AzPy $12 \mathrm{~K}\left(24.1\right.$ vs $23{ }^{\circ} \mathrm{C}$, Figure $6 \mathrm{c})$, revealing a slight increase of the hydrophilicity of the polymer. ${ }^{10,33}$ The thermogram of HS-PN-AzPy $12 \mathrm{~K}$ in neutral water is bimodal (Figure $6 \mathrm{~d}$ ). Both $T_{1}$ and $T_{2}$ shift to higher temperature, compared to their values in the C12-PN-AzPy $12 \mathrm{~K}$ solution. The enthalpy of the transition is larger for solutions of HS-PN-AzPy $12 \mathrm{~K}$ than for C12-PN-AzPy $12 \mathrm{~K}$ solutions ( 5.0 vs $4.3 \mathrm{~kJ} / \mathrm{mol}$ ) (see Figure $6 \mathrm{~d}$ and Table 2), in agreement with the increase in chain hydration observed by $2 \mathrm{D}$ NOE experiments. In summary, although detailed features of the phase transition are different in solutions of monosubstituted and disubstituted AzPy-PNIPAM, in both cases the transition is bimodal. We note, though, that the thermogram of acidic solutions of HS-PN-AzPy $12 \mathrm{~K}(c \approx 1.0 \mathrm{mg} / \mathrm{mL})$ is unimodal (Table 2 and Figure $6 \mathrm{~d}$ ) unlike the thermogram of acidic C12-PN-AzPy $12 \mathrm{~K}$ solutions (Figure $3 \mathrm{~b}$ ). The difference may signal that $\mathrm{HS}-\mathrm{PN}-\mathrm{AzPyH} \mathrm{H}^{+}$chains are sufficiently soluble in cold water to exist as unimers in the dilute regime. ${ }^{43}$ Moreover, the phase transition enthalpy of HS-PN-AzPy in an aqueous solution of $\mathrm{pH} 3$ is similar to that of the control PNIPAM 10K listed in Table $1 .^{14}$

${ }^{1} \mathrm{H}$ NMR spectra of aqueous solutions of C12-PN-AzPy $12 \mathrm{~K}$ and HS-PN-AzPy $12 \mathrm{k}$ were recorded as a function of temperature from 15 to $45{ }^{\circ} \mathrm{C}$ (see Figure S5 in Supporting Information). The resonances of the mainchain protons ( $\delta 1.9$ and $1.5 \mathrm{ppm}$ ) and to a lesser extent those of the side chain methyl gradually disappear upon heating, an indication of the increasingly restricted mobility experienced by the protons of the polymer backbone upon reaching a temperature in the vicinity of the phase transition. For each temperature and each moiety, we calculated the fraction $p$ of immobilized units (see definition in Experimental Section). Plots of the temperature dependence of $p$ for aqueous solutions of C12-PN-AzPy $12 \mathrm{~K}$ $(0.5$ and $3.0 \mathrm{mg} / \mathrm{mL})$ and for HS-PN-AzPy $12 \mathrm{k}(3.0 \mathrm{mg} / \mathrm{mL})$ are presented in Figure 7 (top panel) based on the $\mathrm{CH}_{3}$, main chain, and $\mathrm{CH}$ proton resonances. For solutions of HS-PNAzPy $12 \mathrm{~K}$, the $p$ values of the three groups increase at $25.6^{\circ} \mathrm{C}$, the $T_{\mathrm{cp}}$, and demixing temperature $\left(T_{\mathrm{dem}}\right)$ of the solution (Figure $7 \mathrm{c}$ ). For the most dilute $\mathrm{C} 12-\mathrm{PN}-\mathrm{AzPy} 12 \mathrm{~K}$ solution (Figure $7 \mathrm{a}$ ), the $p$ values increase at $\sim 26{ }^{\circ} \mathrm{C}$, i.e., slightly above $T_{\mathrm{cp}}$. The $p$ value of the main chain group increases slightly with temperature, up to $\sim 33{ }^{\circ} \mathrm{C}$, a temperature corresponding to the second endotherm. The increase of $p$ is more pronounced above this temperature. The $p$ vs temperature profiles of the side groups $\mathrm{CH}_{3}$ and $\mathrm{CH}$ moieties are similar, but the increase of $p$ past $26{ }^{\circ} \mathrm{C}$ is sharper and the fraction of immobile units is larger ( 0.86 vs 0.5 ) compared to the main chain moieties. For the more concentrated C12-PN-AzPy $12 \mathrm{~K}$ solutions (Figure $7 \mathrm{~b})$, the increase of $p$ takes place at a temperature slightly higher than $T_{1}$, implying that in this more concentrated solution, the loss of mobility of micelles clusters occurs at a temperature higher than $T_{1}$.

3.4. Is the Bimodal Phase Transition of the C12-PNAzPy Unique among $\alpha, \omega$-Disubstituted Amphiphilic PNIPAM Derivatives? As stated in the Introduction, the solution properties of $\mathrm{C} 18$-PN-C18 derivatives have been studied extensively by us and others. All thermograms recorded upon heating aqueous solutions of this class of telechelic PNIPAMs (molar mass from $12 \mathrm{kDa}$ to $49 \mathrm{kDa}$ ) reported so far are unimodal. ${ }^{14,32}$ Similarly, aqueous solutions of telechelic PNIPAMs bearing two $n$-tetradecyl chains, such as C14-PN$\mathrm{C} 14(12 \mathrm{kDa})$, possess thermograms with a single endotherm (Figure S6). A distinctive feature of polymers of the C12-PNAzPy series is that one end group is a polycyclic aromatic moiety rather than a linear saturated alkyl chain. To assess the importance of the chemical composition and the bulk of the end-groups, we recorded the thermograms of two $\alpha, \omega$ telechelic PNIPAMs that do not carry linear $n$-alkyl moieties. 
(a)

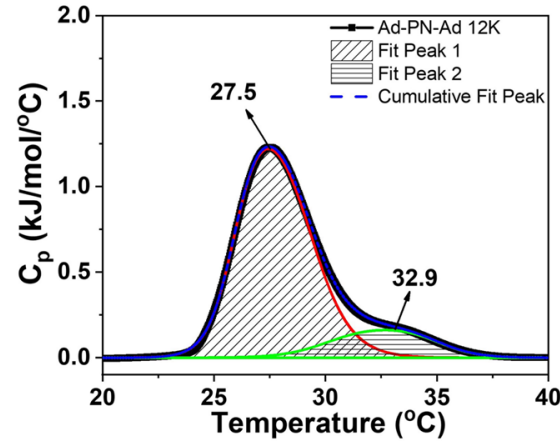

(b)

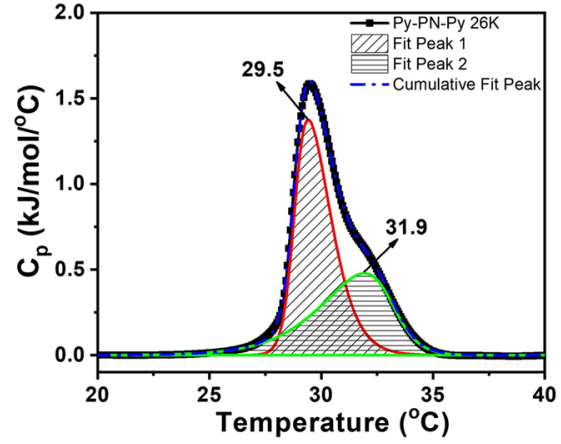

Figure 8. HS-DSC thermograms and peak fitting corresponding to the phase transition of aqueous solutions of (a) Ad-PN-Ad $12 \mathrm{~K}$ (1.0 mg/mL) and (b) Py-PN-Py $26 \mathrm{~K}(1.0 \mathrm{mg} / \mathrm{mL})$.

The end groups were either the tricyclic adamantylethyl group $(\alpha, \omega \text {-diadamantylethyl-PNIPAM, Ad-PN-Ad })^{34}$ or the tetracyclic aromatic 1-pyrenyl-4-butyl group ( $\alpha, \omega$-dipyrenylbutylPNIPAM, Py-PN-Py) ${ }^{33}$ (see structures in Figure 1). Their thermograms (Figure 8) are bimodal, with a low temperature endotherm at $\left(T_{1}=27.5^{\circ} \mathrm{C}, \Delta H_{1}=5.0 \mathrm{~kJ} / \mathrm{mol}\right)$ for Ad-PN-Ad and $T_{1}=29.5{ }^{\circ} \mathrm{C}\left(\Delta H_{1}=2.9 \mathrm{~kJ} / \mathrm{mol}\right)$ for Py-PN-Py, and a high temperature endotherm centered at $T_{2}=32.9^{\circ} \mathrm{C}, \Delta H_{2}=$ $0.9 \mathrm{~kJ} / \mathrm{mol}$ ) in the case of Ad-PN-Ad and $\mathrm{T}_{2}=31.9^{\circ} \mathrm{C}, \Delta \mathrm{H}_{2}=$ $2.1 \mathrm{~kJ} / \mathrm{mol}$ ) in the case of Py-PN-Py.

3.5. Origin of the Transitions. In Table 3, we summarize key features of the responses of endotherm 1 (low temper-

Table 3. Variations of Parameters Associated with the Phase Transition of HM-PNIPAMs and PNIPAM@AuNPs ${ }^{14,22}$ as a Function of Molar Mass and Concentration (Legend: $\uparrow$, Parameter Increases; $\downarrow$, Parameter Decreases; $\rightarrow$, Parameter Remains Constant)

\begin{tabular}{llll} 
polymer & \multicolumn{1}{c}{ C12-PN-AzPy } & $\begin{array}{c}\text { C18-PN- } \\
\text { C18 }\end{array}$ & $\begin{array}{c}\text { PNIPAM@ } \\
\text { AuNPs }^{22}\end{array}$ \\
& $T_{\mathrm{w}} \uparrow$ & $T_{\mathrm{cp}} \uparrow$ & - \\
& $T_{1} \uparrow$ & $T_{\mathrm{m}} \uparrow$ & - \\
& $T_{2} \downarrow$ & - & - \\
& $\Delta H_{1} \rightarrow$ & $\Delta H_{\mathrm{m}} \uparrow$ & - \\
& $\Delta H_{2}$ this arrow must point up & - & - \\
Conc, $\downarrow$ & $T_{\mathrm{cp}} \downarrow$ & $T_{\mathrm{cp}} \downarrow$ & - \\
& $T_{1} \rightarrow$ & $T_{\mathrm{m}} \downarrow$ & $T_{1} \rightarrow$ \\
& $T_{2} \downarrow$ & - & $T_{2} \downarrow$ \\
& $\Delta H_{1} \rightarrow$ & $\Delta H_{\mathrm{m}} \downarrow$ & $\Delta H_{1} \rightarrow$ \\
& $\Delta H_{2} \uparrow$ & - & $\Delta H_{2} \rightarrow$
\end{tabular}

ature) and endotherm 2 (high temperature) to changes of the polymer concentration $(0.1$ to $3.0 \mathrm{mg} / \mathrm{mL})$ and of the molar mass up to $M_{\mathrm{n}} 20 \mathrm{kDa}$. Considering endotherm 1, the enthalpy $\left(\Delta H_{1}\right)$ and the temperature $\left(T_{1}\right)$ of the transition are not affected by changes in polymer concentration. Similarly, an increase in polymer molar mass does not affect the enthalpy of the transition, but it leads to a modest increase of $T_{1}$. Endotherm 1 is sharp and its onset coincides with the solution cloud point Figure 3a), except for the most concentrated solution (Figure $7 \mathrm{~b}$ ). In the case of endotherm 2, an increase in polymer concentration results in a decrease of $T_{2}$ and an increase in the transition enthalpy $\left(\Delta H_{2}\right)$. Moreover, $T_{2}$ decreases and the transition enthalpy $\left(\Delta H_{2}\right)$ increases with increasing polymer molar mass.
Comparing the features of the C12-PN-AzPy thermograms to those of aqueous dispersions of $\mathrm{Au}$ nanoparticles grafted with PNIPAM brushes, the first reported example of a bimodal PNIPAM thermogram, ${ }^{22}$ and aqueous solutions of C18-PN$\mathrm{C} 18$, the structurally related polymer, known to undergo a unimodal phase transition, ${ }^{14,32,44}$ we note important differences. One difference concerns the dependence of the endotherms maximum temperature on the total PNIPAM concentration exhibited by PNIPAM-Au aqueous dispersions: $T_{2}$ decreases with increasing polymer concentration, while $T_{1}$ is not affected. Endotherm 2 was assigned to the dehydration/ collapse of the hydrated external layer of the grafted PNIPAM brush. Endotherm 1 was attributed to the phase transition of the PNIPAM brush layer confined in close vicinity of the $\mathrm{Au} /$ water interface. Since the local concentration of PNIPAM chains in this layer is high, the endotherm is not affected by changes of the PNIPAM solution concentration, contrary with the outer brush layer. In addition, the inner layer is poorly hydrated, as evidenced by the small value of the enthalpy of the corresponding endotherm $1 .^{22}$

For C18-PN-C18 solutions, both the maximum temperature and the enthalpy of the endotherm decrease with increasing PNIPAM concentration. As noted in the original report, ${ }^{13,31}$ the phase transition of $\mathrm{C} 18-\mathrm{PN}-\mathrm{C} 18$ aqueous solutions displays an usual feature: the onset of turbidity $\left(T_{\mathrm{cp}}\right)$ and the PNIPAM dehydration/collapse detected by HS-DSC occur independently (Figure 2a). The collapse and dehydration of the micelle loops (HS-DSC) occurs at a temperature higher than the onset of solution turbidity attributed to the formation of transients clusters of independent hydrated flower micelles formed as a result of thermal fluctuations. The collapse and dehydration of the micelle loops occur at a higher temperature, $T_{\text {dem }}$ (Scheme 1, top). ${ }^{14,32,44}$ As observed in Figure 4a, this is not the case for C12-PN-AzPy aqueous solutions: the onset of solution turbidity and the PNIPAM dehydration/collapse observed by HS-DSC occur at approximately the same temperature. This difference is important as it can be traced to the different morphology of the C18-PN-C18 and C12-PNAzPy micelles.

The $n$-octadecyl end groups of C18-PN-C18 are apolar 21.7Å-long rod (see Figure S7). Micelles of C18-PN-C18 consist of a core of assembled C18 chains surrounded by a layer of spatially confined and poorly hydrated PNIPAM segments. This middle layer is surrounded by loops of hydrated and freely mobile PNIPAM sections. ${ }^{17}$ Their aggregation number ( $N_{\text {agg }}$, where $N$ is the number of polymer chains) is 27 for the 
Scheme 1. Pictorial Representation of the Phase Transition of C18-PN-C18 (Top Panel, Taken from Kujawa et al. ${ }^{32}$ ) and C12PN-AzPy (Bottom Panel) Aqueous Solutions upon Heating ${ }^{a}$

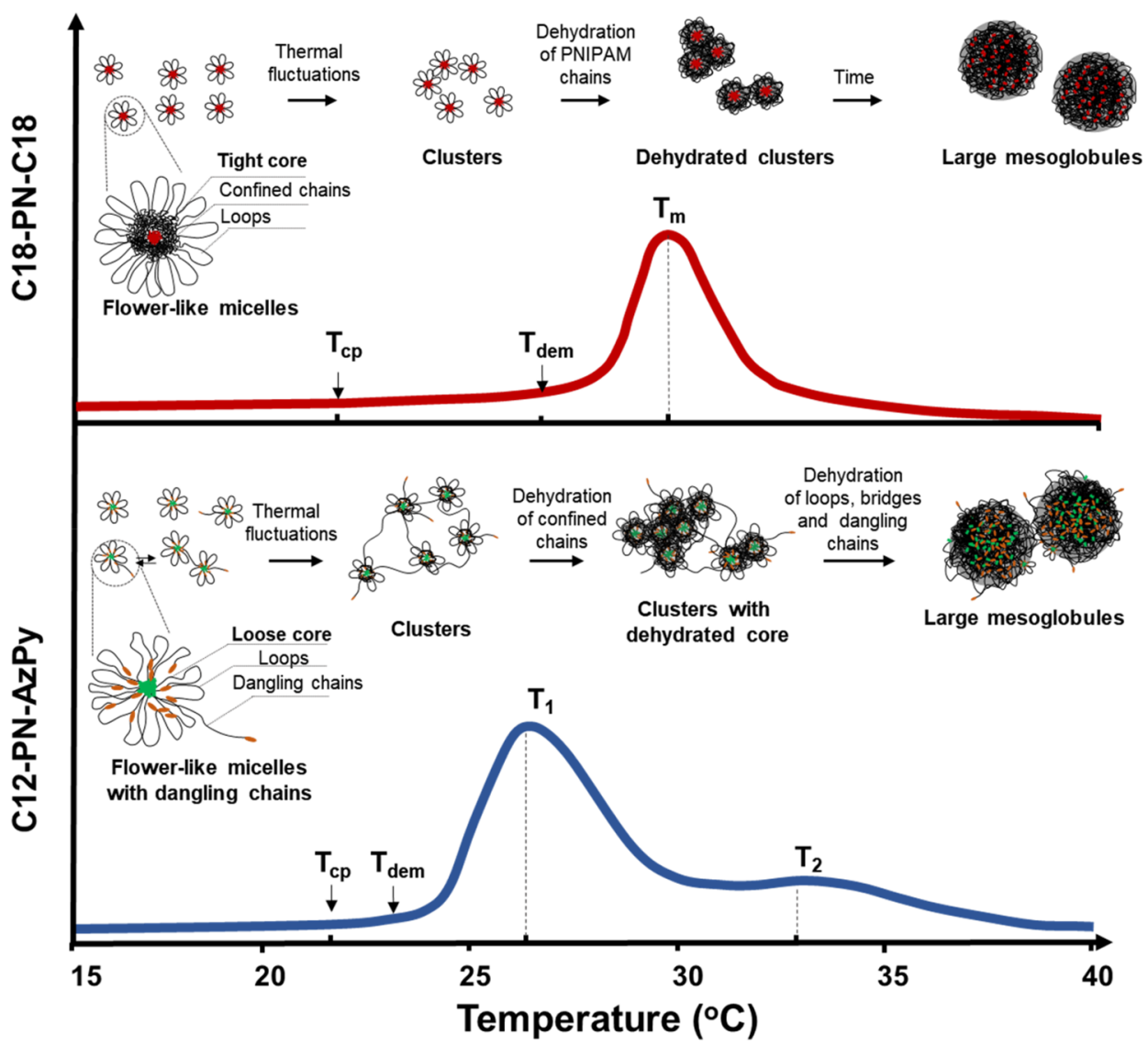

${ }^{a_{T}}$ The temperature scale corresponds to solutions of C12-PN-AzPy $12 \mathrm{~K}$ in water, $\mathrm{pH} 7$.

C18-PN-C18 $12 \mathrm{~K}$ sample, as determined by light scattering analysis. $^{32}$

The $n$-dodecyl group is an apolar chain $\sim 14.0 \AA$ in length. The AzPy group is a polar aromatic chromophore $\sim 8.7 \AA$ in length (Figure $S 7$ ) that possesses a polar pyridine group bound via $\mathrm{N} \cdots \mathrm{H}$ bonds to the amide hydrogen of PNIPAM chains within the micelle shell. ${ }^{35}$ Most of the AzPy groups are located within the PNIPAM shell of the micelle either in close proximity to the core or in the form of small clusters throughout the shell. The $N_{\text {agg }}$ of C12-PN-AzPy $12 \mathrm{~K}$ is 15 . Although $N_{\text {agg }}\left(\right.$ C12-PN-AzPy 12K) $<N_{\text {agg }}($ C18-PN-C18 12K), the $R_{\mathrm{g}}$ and $R_{\mathrm{h}}$ values of C18-PN-C18 $12 \mathrm{~K}$ and C12-PN-AzPy $12 \mathrm{~K}$ are very similar (with both $R_{\mathrm{g}} \sim 15.6 \mathrm{~nm}$ and $R_{\mathrm{h}} \sim 10.5$ $\mathrm{nm}) .{ }^{32,35}$ This is quite remarkable given the difference of length of the end groups. It implies that the core of C12-PNAzPy $12 \mathrm{~K}$ is less compact than the core of C18-PN-C18 micelles and argues against the presence of a layer of spatially confined PNIPAM chains near the micelle core. At any time, a fraction of the azopyridine end groups escape from the micelle dangle in bulk water, reinsert in the same micelle, or form a bridge to a nearby micelle (Scheme 1 , bottom). Upon heating past $T_{\mathrm{cp}} \sim T_{2}$, the solution becomes turbid, and approximately at the same temperature, a large fraction of the PNIPAM chains within the micelles collapse and dehydrate, as evidenced by the $T_{\mathrm{cp}}, T_{\mathrm{dem}}$ coincidence. The PNIPAM bridges and dangling chains dehydrate and collapse at a higher temperature $T_{2}$, possibly triggering further aggregation of the mesoglobules and resulting in an increase of turbidity (Figure 5e). This transition corresponds to endotherm 2. A similar core morphology is adopted also by polymers, such as Ad-PN-Ad and Py-PN-Py, that have end groups smaller or less hydrophobic than $n$-octadecyl chains, such as Ad (3.6 $\AA$ ), and Py $(6.7 \AA)$. The core of these micelles will be malleable, enhancing the mobility of the end-groups and promoting chain escape/reinsertion.

\section{CONCLUSION}

We have derived the likely origin of the unusual bimodal thermogram associated with the heat-induced phase transition of aqueous $\alpha$-azopyridine- $\omega$ - $n$-dodecyl-PNIPAM solutions. The low-temperature $\left(T_{1}\right)$ transition corresponds to the dehydration and collapse of PNIPAM chains within the selfassembled $\alpha$-azopyridine- $\omega$ - $n$-dodecyl-PNIPAM micelles formed in cold water. The temperature $T_{1}$ varies with the molar mass of the polymer, but it does not depend on the polymer concentration. The high temperature endotherm $\left(T_{2}\right)$ is attributed to the dehydration and collapse of hydrated polymer loops, bridges, and dangling chains of the dehydrated micellar clusters that resulted from the first transition $\left(T_{1}\right)$. Other $\alpha, \omega$-disubstituted PNIPAM derivatives bearing short linear or polycyclic substituents also exhibit two-step phase transitions, whereas $\alpha, \omega$-di- $n$-octadecyl-PNIPAM feature a unimodal phase transition, independently of the polymer molar mass. The ability to switch twice over a narrow temperature range from a clear to a turbid to a clear medium, upon heating or cooling, may find applications in sensing, 
especially since azopyridines exhibit fast dark cis-to-trans isomerization. $^{40}$

\section{ASSOCIATED CONTENT}

\section{SI Supporting Information}

The Supporting Information is available free of charge at https://pubs.acs.org/doi/10.1021/acs.macromol.0c00487.

${ }^{1} \mathrm{H}$ NMR spectra of C12-PN-AzPy $12 \mathrm{~K}$ and HS-PNAzPy $12 \mathrm{~K}$; Example of $T_{\mathrm{cp}}$ determination from onset point of transmittance plot; Turbidity curve and its first derivative of $\mathrm{C} 12-\mathrm{PN}-\mathrm{AzPy} 12 \mathrm{~K}$ in dilute aqueous solution; Calculated distance between methyl groups and polymer main chain; VT-NMR data of C12-PNAzPy 12K and HS-PN-AzPy 12K; DSC plot of C14-PN$\mathrm{C} 14$ 12K; Structure and calculated size of different end groups (PDF)

\section{AUTHOR INFORMATION}

\section{Corresponding Author}

Françoise M. Winnik - Laboratory of Polymer Chemistry, Department of Chemistry, PB 55, University of Helsinki, Helsinki FI00140, Finland; International Center for Materials Nanoarchitectonics, National Institute for Material Science, Tsukuba 305-0044, Japan; Department of Macromolecular Science, School of Graduate Studies, University of Osaka, Toyonaka, Osaka 560-0043, Japan; @ orcid.org/0000-00015844-6687; Email: francoise.winnik@helsinki.fi

\section{Authors}

Hao Ren - Key Laboratory of Applied Surface and Colloid Chemistry, Ministry of Education, School of Chemistry and Chemical Engineering, Shaanxi Normal University, Xi'an 710119, P. R. China

Xing-Ping Qiu - Department of Chemistry, University of Montreal, Montreal, Quebec H3C 3J7, Canada

Yan Shi - School of Materials Science and Engineering, Beijing University of Chemical Technology, Beijing 100029, P. R. China

Peng Yang - Key Laboratory of Applied Surface and Colloid Chemistry, Ministry of Education, School of Chemistry and Chemical Engineering, Shaanxi Normal University, Xi'an 710119, P. R. China; 이이이.org/0000-0002-0463-1024

Complete contact information is available at:

https://pubs.acs.org/10.1021/acs.macromol.0c00487

\section{Notes}

The authors declare no competing financial interest.

\section{ACKNOWLEDGMENTS}

H.R. acknowledges funding from the National Natural Science Foundation of China (No. 21905166), China Postdoctoral Science Foundation Grant (No. 2019M653859XB), Natural Science Basic Research Program of Shaanxi (No. 2020JQ-406), and the Fundamental Research Funds for the Central Universities (No. GK202003023). F.M.W. acknowledges the Natural Sciences and Engineering Research Council of Canada for partial support of this work as well as the Osaka University (Japan) International Joint Research Promotion Program. We thank Prof. Heikki Tenhu (Department of Chemistry, University of Helsinki, Finland) and Prof. Takahiro Sato (Department of Macromolecular Chemistry, Osaka University, Japan) for helpful discussions. Drs. P. M. Aguiar and C.
Malveau (University of Montreal, Canada) are acknowledged for their help in setting up the VT-NMR experiments. Initial HS-DSC measurements of aqueous Py-PN-Py solutions were carried out by Dr. E. V. Korchagina (University of Montreal, Canada).

\section{REFERENCES}

(1) Balzani, V.; Credi, A.; Venturi, M. The Bottom-Up Approach to Molecular-Level Devices and Machines. Chem. - Eur. J. 2002, 8, 5524-5532.

(2) Busseron, E.; Ruff, Y.; Moulin, E.; Giuseppone, N. Supramolecular Self-assemblies as Functional Nanomaterials. Nanoscale 2013, 5, 7098-7114.

(3) Brunsveld, L.; Folmer, B. J. B.; Meijer, E. W.; Sijbesma, R. P. Supramolecular Polymers. Chem. Rev. 2001, 101, 4071-4098.

(4) Kim, Y.; Matsunaga, Y. T. Thermo-responsive Polymers and Their Application as Smart Biomaterials. J. Mater. Chem. B 2017, 5, 4307-4321.

(5) Alarcón, C. D. L. H.; Pennadam, S.; Alexander, C. Stimuli Responsive Polymers for Biomedical applications. Chem. Soc. Rev. 2005, 34, 276-285.

(6) Jochum, F. D.; Theato, P. Temperature- and Light-responsive Smart Polymer Materials. Chem. Soc. Rev. 2013, 42, 7468-7483.

(7) Schild, H. G. Poly(N-isopropylacrylamide): Experiment, Theory and Application. Prog. Polym. Sci. 1992, 17, 163-249.

(8) Wu, C.; Wang, X. Globule-to-Coil Transition of a Single Homopolymer Chain in Solution. Phys. Rev. Lett. 1998, 80, 40924094.

(9) Aseyev, V.; Tenhu, H.; Winnik, F. M. Non-ionic Thermoresponsive Polymers in water. In Self Organized Nanostructures of Amphiphilic Block Copolymers II; Springer; 2010; pp 29-89.

(10) Xia, Y.; Burke, N. A. D.; Stöver, H. D. H. End Group Effect on the Thermal Response of Narrow-Disperse Poly(N-isopropylacrylamide) Prepared by Atom Transfer Radical Polymerization. Macromolecules 2006, 39, 2275-2283.

(11) Qiu, X. P.; Koga, T.; Tanaka, F.; Winnik, F. M. New Insights into the Effects of Molecular Weight and End group on the Temperature-induced Phase Transition of Poly(N-isopropylacrylamide) in Water. Sci. China: Chem. 2013, 56, 56-64.

(12) Israelachvili, J. N. Thermodynamic Principles of Self-Assembly. Intermolecular and Surface Forces (3rd ed.) 2011, 503-534.

(13) Cao, Z.; Liu, W.; Gao, P.; Yao, K.; Li, H.; Wang, G. Toward an Understanding of Thermoresponsive Transition Behavior of Hydrophobically Modified N-isopropylacrylamide Copolymer Solution. Polymer 2005, 46, 5268-5277.

(14) Kujawa, P.; Segui, F.; Shaban, S.; Diab, C.; Okada, Y.; Tanaka, F.; Winnik, F. M. Impact of End-Group Association and Main-Chain Hydration on the Thermosensitive Properties of Hydrophobically Modified Telechelic Poly(N-isopropylacrylamides) in Water. Macromolecules 2006, 39, 341-348.

(15) Li, Z.; Johnson, L. M.; Ricarte, R. G.; Yao, L. J.; Hillmyer, M. A.; Bates, F. S.; Lodge, T. P. Enhanced Performance of Blended Polymer Excipients in Delivering a Hydrophobic Drug Through the Synergistic Action of Micelles and HPMCAS. Langmuir 2017, 33, 2837-2848.

(16) Vorobyova, O.; Yekta, A.; Winnik, M. A.; Lau, W. Fluorescent Probe Studies of the Association in an Aqueous Solution of a Hydrophobically Modified Poly(ethylene oxide). Macromolecules 1998, 31, 8998-9007.

(17) Koga, T.; Tanaka, F.; Motokawa, R.; Koizumi, S.; Winnik, F. M. Theoretical Modeling of Associated Structures in Aqueous Solutions of Hydrophobically Modified Telechelic PNIPAM Based on a Neutron Scattering Study. Macromolecules 2008, 41, 9413-9422.

(18) De Gennes, P. A Second Type of Phase Separation in Polymer Solutions. C. R. Acad. Sci., Ser. II: Mec., Phys., Chim., Sci. Terre Univers 1991, 313, 1117-1122.

(19) Ohnsorg, M. L.; Ting, J. M.; Jones, S. D.; Jung, S.; Bates, F. S.; Reineke, T. M. Tuning PNIPAm Self-assembly and Thermoresponse: 
Roles of Hydrophobic End-groups and Hydrophilic Comonomer. Polym. Chem. 2019, 10, 3469-3479.

(20) Lang, X.; Patrick, A. D.; Hammouda, B.; Hore, M. J. Chain Terminal Group Leads to Distinct Thermoresponsive Behaviors of Linear PNIPAM and Polymer Analogs. Polymer 2018, 145, 137-147.

(21) Shan, J.; Zhao, Y.; Granqvist, N.; Tenhu, H. Thermoresponsive Properties of N-Isopropylacrylamide Oligomer Brushes Grafted to Gold Nanoparticles: Effects of Molar Mass and Gold Core Size. Macromolecules 2009, 42, 2696-2701.

(22) Shan, J.; Chen, J.; Nuopponen, M.; Tenhu, H. Two Phase Transitions of Poly(N-isopropylacrylamide) Brushes Bound to Gold Nanoparticles. Langmuir 2004, 20, 4671-4676.

(23) Zhu, P. W.; Napper, D. H. Experimental Observation of Coilto-Globule Type Transitions at Interfaces. J. Colloid Interface Sci. 1994, 164, 489-494.

(24) Xue, N.; Qiu, X.; Chen, Y.; Satoh, T.; Kakuchi, T.; Winnik, F. $M$. Effect of chain architecture on the phase transition of star and cyclic poly(N-isopropylacrylamide) in water. J. Polym. Sci., Part B: Polym. Phys. 2016, 54, 2059-2068.

(25) Luo, S.; Xu, J.; Zhu, Z.; Wu, C.; Liu, S. Phase Transition Behavior of Unimolecular Micelles with Thermoresponsive Poly $(\mathrm{N}$ isopropylacrylamide) Coronas. J. Phys. Chem. B 2006, 110, 91329139.

(26) Luo, S.; Hu, X.; Ling, C.; Liu, X.; Chen, S.; Han, M. Multiarm Star-like Unimolecular Micelles with a Dendritic Core and a Dual Thermosensitive Shell. Polym. Int. 2011, 60, 717-724.

(27) Xu, J.; Luo, S.; Shi, W.; Liu, S. Two-Stage Collapse of Unimolecular Micelles with Double Thermoresponsive Coronas. Langmuir 2006, 22, 989-997.

(28) Portehault, D.; Petit, L.; Hourdet, D. Synthesis and Selfassembly Processes of Aqueous Thermoresponsive Hybrid Formulations. Soft Matter 2010, 6, 2178-2186.

(29) Yang, Z.; Xie, J.; Zhou, W.; Shi, W. Temperature Sensitivity and Drug Encapsulation of Star-shaped Amphiphilic Block Copolymer Based on Dendritic Poly(ether-amide). J. Biomed. Mater. Res., Part A 2009, 89, 988-1000.

(30) Tang, H.; Zhang, B.; Wu, P. On the Two-step Phase Transition Behavior of the Poly(N-isopropylacrylamide) (PNIPAM) Brush: Different Zones with Different Orders. Soft Matter 2014, 10, 72787284.

(31) Nuopponen, M.; Kalliomaki, K.; Aseyev, V.; Tenhu, H. Spontaneous and Thermally Induced Self-organization of A-B-A Stereoblock Polymers of N-Isopropylacrylamide in Aqueous Solutions. Macromolecules 2008, 41, 4881-4886.

(32) Kujawa, P.; Tanaka, F.; Winnik, F. O. M. TemperatureDependent Properties of Telechelic Hydrophobically Modified Poly(N-isopropylacrylamides) in Water: Evidence from Light Scattering and Fluorescence Spectroscopy for the Formation of Stable Mesoglobules at Elevated Temperatures. Macromolecules 2006, 39, 3048-3055.

(33) Fowler, M.; Duhamel, J.; Qiu, X. P.; Korchagina, E.; Winnik, F. M. Temperature Response of Aqueous Solutions of Pyrene Endlabeled poly(N-isopropylacrylamide)s Probed by Steady-state and Time-resolved Fluorescence. J. Polym. Sci., Part B: Polym. Phys. 2018, 56, 308-318.

(34) Bennevault, V.; Huin, C.; Guegan, P.; Evgeniya, K.; Qiu, X. P.; Winnik, F. M. Temperature Sensitive Supramolecular Self-assembly of per-6-PEO-beta-cyclodextrin and $\alpha, \omega$-di-(adamantylethyl)poly(Nisopropylacrylamide) in water. Soft Matter 2015, 11, 6432-6443.

(35) Ren, H.; Qiu, X.; Shi, Y.; Yang, P.; Winnik, F. M. pHDependent Morphology and Photoresponse of Azopyridine-Terminated Poly(N-isopropylacrylamide) Nanoparticles in Water. Macromolecules 2019, 52, 2939-2948.

(36) Segui, F.; Qiu, X.; Winnik, F. M. An Efficient Synthesis of Telechelic Poly(N-isopropylacrylamides) and its Application to the Preparation of $\alpha, \omega$-dicholesteryl and $\alpha, \omega$-dipyrenyl polymers. $J$. Polym. Sci., Part A: Polym. Chem. 2008, 46, 314-326.

(37) Bouzidi, L.; Boodhoo, M.; Humphrey, K. L.; Narine, S. S. Use of First and Second Derivatives to Accurately Determine Key
Parameters of DSC Thermographs in Lipid Crystallization Studies. Thermochim. Acta 2005, 439, 94-102.

(38) Obeid, R.; Tanaka, F.; Winnik, F. M. Heat-Induced Phase Transition and Crystallization of Hydrophobically End-Capped Poly(2-isopropyl-2-oxazoline)s in Water. Macromolecules 2009, 42, 5818-5828.

(39) Spěváček, J. NMR Investigations of Phase Transition in Aqueous Polymer Solutions and Gels. Curr. Opin. Colloid Interface Sci. 2009, 14, 184-191.

(40) Ren, H.; Qiu, X.; Shi, Y.; Yang, P.; Winnik, F. M. Light, Temperature, and $\mathrm{pH}$ control of Aqueous Azopyridine-terminated Poly(N-isopropylacrylamide) Solutions. Polym. Chem. 2019, 10, 5080-5086.

(41) Halperin, A.; Kröger, M.; Winnik, F. M. Poly(N-isopropylacrylamide) Phase Diagrams: Fifty Years of Research. Angew. Chem., Int. Ed. 2015, 54, 15342-15367.

(42) Morris, K. F.; Froberg, A. L.; Becker, B. A.; Almeida, V. K.; Tarus, J.; Larive, C. K. Using NMR to Develop Insights into Electrokinetic Chromatography. Anal. Chem. 2005, 77, 254A-263A.

(43) Sambe, L.; Stoffelbach, F.; Lyskawa, J.; Delattre, F.; Fournier, D.; Bouteiller, L.; Charleux, B.; Cooke, G.; Woisel, P. Host-Guest Modulation of the Micellization of a Tetrathiafulvalene-Functionalized Poly(N-isopropylacrylamide). Macromolecules 2011, 44, 65326538.

(44) Nojima, R.; Sato, T.; Qiu, X.; Winnik, F. M. Light Scattering Evidence for the Random Association of Flower Micelles of a Telechelic Hydrophobically Modified Poly(N-isopropylacrylamide) in Dilute Aqueous Solution. Macromolecules 2008, 41, 292-294. 